\title{
Research on Application of 3D Printing Materials in Product Design*
}

\author{
Yifeng Du \\ Zhuhai College of Jilin University \\ Zhuhai, China 519041
}

\begin{abstract}
Rapid prototyping technology of 3D printing not only substitutes the traditional handcraft manufacturing model, but also renovates the traditional industry and successfully introduces information technology. This article starts with connotation interpreting of $3 \mathrm{D}$ print, analyzing the design flow of 3D print technology, besides, it analyzes materials for 3D printing, according to characteristics of the materials, and it conducts detailed classification and analysis, exploring the application of 3D printing materials in product design.
\end{abstract}

\section{Keywords-3D print; product design; material; application}

\section{INTRODUCTION}

$3 \mathrm{D}$ print rapid prototyping is raised on the basis of $2 \mathrm{D}$ print and it decomposes complicated 3D fabrication into simple 2D fabrication, it is a technique developed on the basis of micro-droplet jetting, similar to print heads, yet the difference is, the array scanning jetting technology can not only conduct 2D motion but also conduct vertical motion, the reason for it to form $3 \mathrm{D}$ entity is its difference from traditional 2D printers, what printers jet is ink yet, what $3 \mathrm{D}$ print jet is binder.

\section{3D PRINT TECHNOLOGY}

Traditional model making needs a long time, which consist of fussy steps including design, 3D modeling, material selection, spare part making and assembly and so on. Compared to traditional patterns, the $3 \mathrm{D}$ making and rendering in the product design industry have made a considerable progress, after all, it is not material object. Therefore, product design companies started to make handmade models which yet generally need a long period with complicated procedures, and as a result, the hand-made models are expensive.

3D printing rapid prototyping is a substitution of traditional handcraft manufacturing, a renewal of traditional industry and a successful practice of IT. Modern industries are facing the situation that life cycles of products are becoming shorter and shorter, and the rapid prototyping has changed previous model making methods, and the combination of 3D printing technology and models will bring huge impact on the industries, and the production of

*Project Source: Innovative Capability Cultivation Project of Zhuhai College Jilin University Research on Application of 3D Printing Technology in Product R\&D (Project No: 2016XJCQCX18). complicated models will no longer depend on any mould and tool.

\section{3D PRINT DESIGN FLOW}

Traditional product design flow is very complicated, first of all, according to the long term development strategy and economic goal, the enterprise will confirm the need of target market to launch one or more product concept development, the define the product system and modularize the product After confirming the product concept, conduct more detailed design of new product scheme, the process long and complicated, so in order to accelerate the product $R \& D$ speed, many enterprises try best to shorten the R\&D period and start to consider to flatten the production flow so as to make the products of its own occupy the market rapidly.

3D print changes the general flow of traditional product design, with the premise given, products are clearly positioned, in the initial concept design stage, as long as the data of special target clients are collected, details of the product can be confirmed, which reduce repeated tests and evaluation, and the products can be delivered to target clients directly. Therefore the design follow of manufacturing systems on the basis of 3D print will be more flattened and targeted, it will greatly shorten the product R\&D time and improve the product R\&D efficiency.

\section{MATERIALS FOR 3D PRINTING TECHNOLOGY}

Compared to traditional manufacturing technique, 3D print needs no molds made in advance, no removal of lots of materials in making or not undergo complicated forging before final products, therefore, it can achieve optimized structure in production, saving of materials and resources. $3 \mathrm{D}$ printing technology applies to new product $\mathrm{R} \& \mathrm{D}$, making of fast-speed single parts and small batches of parts, making of parts with complicated figures, mold design and making, as well as making of materials hard to process, external design examination, assembling test and reversing engineering. Materials are foundation of 3D print, and bottles restricting the development of 3D printing technology, therefore, it's necessary to conduct specific researches on materials.

3D printing technology cannot be separated from 3D printing materials, materials are key for successful print and determine whether 3D print can be widely used or not 
Currently main materials for $3 \mathrm{D}$ print include engineering plastics, photosensitive resin, rubber materials, metal materials and ceramic materials, and in addition, food materials such as artificial bone meal, cell biology materials, colored plaster and granulated sugar are also widely used in 3D print.

The plastics, resin and plasters used in 3D print are all materials needing special process and technique, which differ from general materials. First of all, on appearance, all look layered, striped, powdered or liquid. Generally powdered materials have some specification and requirements such as highly round so as to keep powder flowing well, and the gain sizes of materials used shall be $1-100 \mu \mathrm{m}$.

\section{A. Engineering Plastics}

Engineering plastics is often used in 3D print, which has sound performances such as impact resistance, high temperature resistance, high hardness and anti-aging, and it is the most widely material for $3 \mathrm{D}$ print, besides, it is often used to make industrial models.

ABS is a kind of thermoplastic engineering material and commonly used, based on FDM (fused deposition modeling) for prototyping, it has strength as high strength, sound toughness and shock resistance, and normal temporary for deformation exceeds $90^{\circ} \mathrm{C}$, besides, it can processed technically such as spray painting, drilling, tapping, electroplate and so on. In addition, it has diverse colors optional such as black, white, gray, red and blue, which are widely used in $3 \mathrm{D}$ print.

Another thermoplastic material is PC material, if ABS is thought as a thermoplastic material, then PC material can be representative of thermoplastic materials, and it has characteristics such as high temperature resistance, corrosion prevention, impact resistance and high strength, and its physical strength is high than ABS plastic by $60 \%$, so it is an extremely quality material for fabrication and making of spare parts. The material can be used in diverse fields such as aerospace, medical instrument and apparatus. Advantages of the material are products made of it through 3D print can be assembled directly, and the sole defect is its color, one color, that is, white only.

Compared to general plastic materials, nylon glass fiber material has strong tensile property, and in addition it has stronger heat resistance, uneasy for deformation, so it has been widely used in auto and household appliance manufacturing.

PC-ABS material is also a plastic material, which is a new 3D printing material developed on the basis of ABS plastic, but it has higher heat resistance than ABS plastic and PC plastic. In addition, it shows sound physical performance during the printing, with higher strength, it is an excellent 3D material and widely used in communications, household appliance and auto making.

Another thermoplastic material that can be used for 3D printing is PC-ISO, which is mostly used in medical field, and it is a white thermoplastic material. It is mainly used for making of medical instruments and apparatus and assistance to medical tools, in addition, it can be also in medical teaching. For example, the making of teeth model in dentistry, operation simulation and medical teaching have been widely used. Because PC-ISO has sound physical performance, currently it has also been used in food and drug packaging.

Though PSU material is also a plastics, yet, differing from other materials, it is specially used in aerospace and traffic tools making. For such material has special performance and extremely stable performance, in addition, its most important characteristics is heat resistance and corrosion prevention, having strong plasticity, able to bring better digital experience, so it has been widely used in some professional fields.

\section{B. Photosensitive Resin}

Photosensitive resin materials contain chemical substance named photosensitizer, which consists of monomer polymer and prepolymer, and it is also called UV resign material. Basic principle: materials are exposed to UV-light with some wavelength to produce a polymerization reaction, and finally the material will be completely solidified for formation. It is special material, good at waterproofing, though it looks like liquid, yet after completion of making, the product has characteristics of high temperature resistance and corrosion prevention.

\section{Rubber Material}

Rubber material has high elasticity and it is of high strength, toughness and flexibility suitable for 3D printing. It is commonly used in tyre making or auto inner decoration; in addition, it can be often seen in consumed electronic products, and its molecular density decides its special elasticity and toughness, so it is a material of greatly fine tear resistance and tension resistance.

\section{Metal Material}

The rapid development of 3D printing technology drives the development of 3D printing materials, metal material is a new 3D printing material produced on the background. Relying 3D printing equipment, metal material can be processed into metal parts with extremely high precision. However, for the 3D printing technology, metal material is mostly metal powder, for example, the gold and silver used in jewelry printing belong to powder materials. This metal powder material has unique characteristics of its own: high purity, highly round, narrow grain size distribution, low oxygen content. Currently metal powder materials used in 3D printing are mainly titanium alloy, cobalt-chromium alloy, stainless steel and aluminum alloy and so on.

Generally titanium is mainly used in special fields, it can be used in the aircraft manufacturing and aerospace such as rocket parts, key parts of missiles and aircrafts. Titanium has sound corrosion resistance, able to resist high temperature, besides, it owns excellent mechanical properties, and materials made of it have characteristics such as high strength, corrosion resistance and high temperature resistance. Currently with the rapid development of 3D 
printing technology, titanium metal can already be used to produce spare parts with the size of $1 \mathrm{~mm}$ precision, and the precision and fineness can compete with traditional forging process.

Stainless steel metal powder is a material which is often used in $3 \mathrm{D}$ printing with higher cost-effective. It has the characteristics such as anti-steam, corrosion resistance and high temperature resistance, as well as higher physical strength. Its strength lies in the making of products with large sizes, and it has been widely used in diver fields of product manufacturing.

\section{E. Ceramic Material}

Ceramic material is widely used in industrial design, and it has excellent characteristics such as extremely high strength, low density, chemical stability, as well as corrosion resistance and high temperature resistance, and it is an advanced material used in aerospace, auto, biological manufacturing and so on. However, for the ceramic production process has higher requirements, high production cost as well as defects of materials as hard and fragile, which become barriers for most people. However, the coming of 3D print makes the production of ceramic products simpler with a great umber of production costs reduced. Ceramic powder is used in 3D printing, which consists of ceramic powder and binder powder. After laser sintering, the ceramic products will be placed into the temperature control furnace, after treatment under high temperature, and it can get the final finished products. However, during the burning, more attention shall be paid the ratio between ceramic powder and binder powder which will affect the stability of ceramic components. In addition, the original size of ceramics, ceramic surface texture and structure will also affect the stability and sintering of ceramics, so it has an extremely high requirement in the production process. Currently, the 3D print-based ceramic rapid prototyping process is far to be perfect, still in the stage of exploration, with the research of the people and technical progress, it can be expected that the application of ceramic materials in $3 \mathrm{D}$ print will be promising in the future.

\section{CONCLUSION}

3D printing technology has not only shortened the product development period and reduced the product $R \& D$ costs but also drive the enterprises to quickly convert design ideas into physical objects and evaluate and modify new products through 3D models; it has greatly improved the efficiency of product $R \& D$ and avoided the huge economic loss caused by the failure of product $R \& D$, besides, it can meet the personalized and diverse needs of customers and raise the enterprise' competitiveness in markets. With the technological progress and social development, there will be more and more new materials and processes for 3D print, and it will be certain to promote the rapid development of 3D printing technology and launch a new round of technological revolution.

\section{REFERENCES}

[1] Wang Yungan, Wang Yi, 3D Printing Technology (3D Print, Printing World, Printing Future) [M]. Shanghai: Huazhong University of Science \& Technology Press, 2013.

[2] Yang Jiquan, Dai Ning, Hou Liya, 3D Print Design and Making [M].Beijing: Science Press, 2015.

[3] Wang Yungan, 3D Printing \& Free Form Fabrication [M]. Beijing: China Machine Press, 2012. 